\title{
The Safety and Efficacy of Lansoprazole plus Metoclopramide among Neonates with Gastroesophageal Reflux Disease Resistant to Conservative Therapy and Monotherapy: A Clinical Trial
}

\author{
Peymaneh Alizadeh Taheri ${ }^{(D},{ }^{1}$ Elahe Validad $\left(\mathbb{D},{ }^{2}\right.$ and Kambiz Eftekhari ${ }^{3}{ }^{3}$ \\ ${ }^{1}$ Department of Neonatology, Tehran University of Medical Sciences, Bahrami Children Hospital, Tehran, Iran \\ ${ }^{2}$ Department of Pediatrics, Tehran University of Medical Sciences, Bahrami Children Hospital, Tehran, Iran \\ ${ }^{3}$ Department of Gastroenterology, University of Medical Sciences, Bahrami Children Hospital, Tehran, Iran \\ Correspondence should be addressed to Peymaneh Alizadeh Taheri; p.alizadet@yahoo.com
}

Received 10 July 2020; Revised 18 November 2020; Accepted 4 January 2021; Published 16 January 2021

Academic Editor: Lavjay Butani

Copyright (c) 2021 Peymaneh Alizadeh Taheri et al. This is an open access article distributed under the Creative Commons Attribution License, which permits unrestricted use, distribution, and reproduction in any medium, provided the original work is properly cited.

\begin{abstract}
Background. Gastroesophageal reflux disease (GERD) is one of the most common problems in neonates. The main clinical manifestations of neonatal GERD are frequent regurgitation or vomiting associated with irritability, crying, anorexia or feeding refusal, failure to thrive, arching of the back, and sleep disturbance. Aims. The efficacy and safety of ranitidine plus metoclopramide and lansoprazole plus metoclopramide in reducing clinical GERD symptoms based on I-GERQ-R scores in neonatal GERD resistant to conservative and monotherapy. Study Design. This study was a randomized clinical trial of term neonates with GERD diagnosis (according to the final version of the I-GERQ-R), resistant to conservative and monotherapy admitted to Bahrami Children Hospital during 2017-2019. Totally, 120 term neonates (mean age $10.91 \pm 7.17$ days; girls $54.63 \%$ ) were randomly assigned to a double-blind trial with either oral ranitidine plus metoclopramide (group A) or oral lansoprazole plus metoclopramide (group B). The changes of the symptoms and signs were recorded after one week and one month. At the end, fifty-four neonates in each group completed the study and their data were analyzed. Results. There was no significant difference in demographic and baseline characteristics between the two groups. The response rate of "lansoprazole plus metoclopramide" was significantly higher than "ranitidine plus metoclopramide" (7.44 \pm 3.86 score vs. $9.3 \pm 4.57$ score, $p=$ $0.018)$ after one week and $(2.41 \pm 3.06$ score vs. $4.5 \pm 4.12$ score, $p=0.003)$ after one month (primary outcome). There were no drug adverse effects in either group during intervention (secondary outcome). Conclusions. The response rate was significant in each group after one week and one month of treatment, but it was significantly higher in the "lansoprazole plus metoclopramide" group compared with the "ranitidine plus metoclopramide" group. The combination of each acid suppressant with metoclopramide led to a higher response rate in comparison with monotherapy used before intervention. This study has been registered at the Iranian Registry of Clinical Trails (RCT20160827029535N3).
\end{abstract}

\section{Introduction}

Gastroesophageal reflux (GER) is a physiologic reverse passage of gastric contents into the esophagus with or without regurgitation and/or vomiting $[1,2]$. It is commonly observed during the first year of life and almost happens in $65 \%$ of infants at the age of 3-6 months [2]. Gastroesophageal reflux disease (GERD) occurs when troublesome symp- toms or conditions complicate the physiologic GER [1-4]. The main clinical manifestations of neonatal GERD include frequent regurgitation or vomiting associated with irritability, excessive crying, anorexia or feeding refusal, hematemesis, failure to thrives, Sandifer syndrome, anemia, sleep disturbance, coughing, choking, wheezing, stridor, apnea spells, recurrent pneumonia aspiration, recurrent otitis media, or upper respiratory tract symptoms $[1,5,6]$. 
Malformations of the central nervous system (CNS) and gastrointestinal tract (e.g., esophageal atresia and congenital diaphragmatic hernia), a positive family history of GERD, cystic fibrosis, hiatal hernia, family history of severe GERD, neurologic impairment, drugs (e.g., sedatives and muscle relaxants), and prematurity are factors that increase the risk of GERD in infants $[3,4]$.

Acid suppressants, including histamine-2 receptor antagonists (H2RAs) and proton pump inhibitors (PPIs), have been used as a pharmacologic treatment of pediatric GERD to induce symptomatic relief and normal growth and to prevent its complications and recurrence [7]. According to the recent guidelines, a 2-4-week trial of a PPI or H2RA is recommended for infants with significant regurgitation accompanied with symptoms such as unexplained feeding problems, troubled behavior, and poor weight gain [4]. PPIs (e.g., lansoprazole) facilitate gastric emptying and inactivate $\mathrm{H}+/ \mathrm{K}+-\mathrm{ATPase}$ in the gastric parietal cells canaliculi, leading to inhibition of gastric acid production and secretion $[8,9]$. PPIs induce a more vigorous inhibition of acid secretion, have a longer duration of action, and cause fewer complications and no tachyphylaxis compared to H2RAs $[5,10]$. Prokinetics increase the LES tone and gastric emptying [11]. Among prokinetics, although metoclopramide may induce irritability, drowsiness, oculogyric crisis, dystonic reaction, apnea, and emesis in infants, these adverse reactions are only induced with prolonged or high-dose metoclopramide exposure [12]. On the other hand, two other prokinetics including domperidone and cisapride may induce cardiac arrhythmia and are prohibited to be used in the USA $[13,14]$. Macrolides are known as prokinetics, but they may also induce cardiac arrhythmia in long-term exposure [15]. Totally, metoclopramide is a safe prokinetic if it is administered with shortduration and low-dose amount, so we preferred to use it in this study.

There are still controversies about the management of neonatal GERD. To the best of our knowledge, very few clinical trials have compared the effectiveness of PPIs and H2RAs in pediatric GERD, especially in neonates and infants $[16,17]$. Since no study has compared the efficacy and safety of metoclopramide plus ranitidine with metoclopramide plus lansoprazole in the management of neonatal GERD resistant to conservative therapy and monotherapy, this study was carried out.

\section{Patients and Methods}

This double-blind randomized controlled trial was conducted to compare the effectiveness of metoclopramide plus lansoprazole and metoclopramide plus ranitidine for GERD in term neonates.

2.1. Subjects. One hundred and twenty term neonates (postnatal age $<28$ days, gestational age: $38-40$ weeks) that presented to Bahrami Children's Hospital during 2016-2019 with a clinical diagnosis of GERD were enrolled in this study. The participants in both groups were fed with breast milk. The frequency of feeding was every two hours.
All patients were resistant to conservative therapy plus ranitidine or conservative therapy plus lansoprazole as the first line of treatment before intervention. The clinical improvement was $<50 \%$ as defined as $<50 \%$ reduction rate in the I-GERQ-R score (Table 1) before intervention. The conservative therapy included postural change, reduction of the feeding volume, and increasing the frequency of feedings (Table 1). Metoclopramide was added to ranitidine in patients of group A who had received ranitidine before intervention. On the other hand, metoclopramide was added to lansoprazole in patients of group B who had received lansoprazole before intervention.

The neonates with any significant underlying conditions (e.g., major congenital abnormalities and gastrointestinal or neurological disorders) or diseases (e.g., sepsis and cow's protein milk allergy), those who required invasive or noninvasive ventilation, and patients who administered any muscle relaxant or sedative medication were excluded from the study.

The number of participants was determined by a prospective power analysis, assuming a power of at least $80 \%$, a 2 -sided alpha of 0.05 , and treatment response based on the studies of Springer et al. [18] and Famouri et al. [19].

2.2. Diagnosis. In this study, a diagnosis of GERD was made according to the final version of the I-GERQ-R and validity clinical score consisting of 12 items including the frequency, amount, and discomfort attributable to spit up (3 items), refusal or stopping feeding (2 items), crying and fussing (3 items), hiccups (1 item), arching back (1 item), and stopping breathing or color change ( 2 items). The items in the IGERQ-R are summed, yielding a total score ranging from 0 to 42 with a cut point $>15$ scores (Table 1) [20].

A significant rate of response to combination therapy also confirmed the diagnosis of GERD in each patient. Other diagnoses were ruled out based on the clinical manifestations of the patients, for example, if there were vomiting, apnea, or failure to thrive; clinical examination, lab tests, brain sonography, etc. were used to rule out sepsis, intraventricular hemorrhage, and other causes. The duration of conservative treatment and monotherapy was about 3-7 days each according to a careful balance of risks and benefits between the severity of clinical problems and the response rate. The term "resistant to conservative therapy and monotherapy" was applied when the clinical improvement was $<50 \%$ as defined as $<50 \%$ reduction rate in the I-GERQ-R score (Table 1 ) before intervention.

2.3. Trial. The study protocol was approved by the Research Ethics Committee of Tehran University of Medical Sciences (IR.TUMS.MEDICINE.REC.1396.3714). It was also registered in the Iranian Registry of Clinical Trails (RCT20160827029535N3). Written informed consent was obtained from parents or guardians of all infants before enrollment. They were explained about the study and procedures.

Mothers were assured of the confidentiality of their information, and they were also made to understand that 
TABLE 1: Correlations between daily symptom diary and the I-GERQ-R.

\begin{tabular}{ll}
\hline I-GERQ-R items & Scoring \\
Daily symptom diary & $0-3$ \\
\hline Item 1. How often did baby spit up? & $0-4$ \\
Item 2. How much did baby spit up? & $0-4$ \\
Item 4 . How often was spitting up uncomfortable for the baby? & $0-4$ \\
Item 5 . How often did the baby refuse a feeding when hungry? & $0-4$ \\
Item 6. How often did the baby stop eating soon after eating even when hungry? & $0-4$ \\
Item 8 . Did the baby cry a lot during or within 1 hour after feedings? & $0-4$ \\
Item 9. Did the baby cry or fuss more than usual? & $0-3$ \\
Item 10. On average how long did the baby cry or fuss during a 24-hour period? & $0-4$ \\
Item 11. How often did the baby have hiccups? & $0-4$ \\
Item 12. How often did the baby have episodes of arching back? & $0-4$ \\
Item 13. Has the baby stopped breathing while awake or struggled to breathe? & $0-2$ \\
Item 14. Has the baby turned blue or purple? & \\
\hline
\end{tabular}

Regurgitation and crying items comprise $\sim 50 \%$ of total possible points; >> needed for diagnosis. Total possible scoring: 42 (22); cut point > 15 .

participation was voluntary and participants could opt out at any stage of the study.

One hundred and twenty term neonates who met the inclusion and exclusion criteria were randomly assigned (in blocks of two per site) to a double-blind clinical trial to receive lansoprazole plus metoclopramide or ranitidine plus metoclopramide for a 30-day period. The random allocation sequence was generated by an independent statistician. The medical clinician, the researcher who collected the data, and the statist who analyzed the data were blind to the study.

Sixty neonates in group A received oral ranitidine $2 \mathrm{mg} / \mathrm{kg} /$ dose three times daily plus metoclopramide $0.15 \mathrm{mg} / \mathrm{kg} /$ dose three times daily, and sixty neonates in group B received oral lansoprazole $0.5 \mathrm{mg} / \mathrm{kg} / \mathrm{dose}$ twice daily plus metoclopramide $0.15 \mathrm{mg} / \mathrm{kg} /$ dose three times daily. Before intervention, a checklist including demographic data (age, gender, birth weight, and weight at presentation) and GERD symptoms and signs according to I-GERQ-R scores was filled by a neonatologist (clinical researcher). The same neonatologist evaluated the clinical manifestations of patients according to I-GERQ-R scores after one week and one month to define whether improvement remains stable or continues to improve significantly.

In each group, six patients lost to follow-up or discontinued intervention. At the end, fifty-four neonates in each group completed the study and their data were analyzed (Figure 1).

The primary outcomes were changes in the total number of GERD-related signs and symptoms from baseline to the end of the intervention. The secondary outcomes were defined as complications in either group following oral administration of metoclopramide, ranitidine, and lansoprazole.

2.4. Data Analysis. The SPSS for Windows version 21.0 was used for data analysis (SPSS Inc., Chicago, IL, USA). Descriptive data are reported as mean and standard deviation (SD) for numerical and number (percent) for categorical data. Posttreatment results were compared against baseline data using a two-sided paired $t$-test for differences in the mean values and chi-square test and Fisher's exact test (two sided) for differences in the percentage of response to treatment. A $p$ value of $<0.05$ was considered significant.

\section{Results}

In this double-blind randomized controlled trial, 108 term newborns (mean age: $10.91 \pm 7.17$ days, range: $1-29$ days, girls: $57.4 \%$ ) were enrolled. The mean birth weight of the study subjects was $3204.5 \pm 399.6 \mathrm{~g}$. All participants were evaluated by the attending neonatologist and diagnosed with GERD based on the clinical criteria of the I-GERQ-R and validity score. The neonates were randomized to receive metoclopramide + ranitidine $(n=54$, ranitidine was administered at a dose of $2 \mathrm{mg} / \mathrm{kg} /$ dose three times daily) or metoclopramide + lansoprazole $(n=54$, lansoprazole was administered at a dose of $0.5 \mathrm{mg} / \mathrm{kg} /$ dose twice daily). There was no significant difference in demographic data and baseline characteristics between the two groups (Table 2).

Pre- and postintervention GERD-associated clinical manifestations according to the intervention group are compared in Tables 3 and 4 . In the present study, the total clinical improvement was $>50 \%$ after one week and $>70 \%$ after one month of intervention, as defined as a reduction in the IGERQ-R score. The findings showed that the response rate was significantly higher in the lansoprazole plus metoclopramide group compared to the ranitidine plus metoclopramide group after one week $(64.38 \% \pm 15.07 \%$ vs. $52.14 \% \pm 21.24 \%$, " $p \leq 0.001$ ") and after one month $(74.3 \% \pm 23.3 \%$ vs. $88.47 \%$ $\pm 13.18 \%$, “ $p \leq 0.001 ”)$. Treatment with lansoprazole plus metoclopramide improved all clinical manifestations better than ranitidine plus metoclopramide after one week while treatment with lansoprazole plus metoclopramide improved all clinical manifestations better than ranitidine plus metoclopramide except feeding refusal, vomiting associated with 


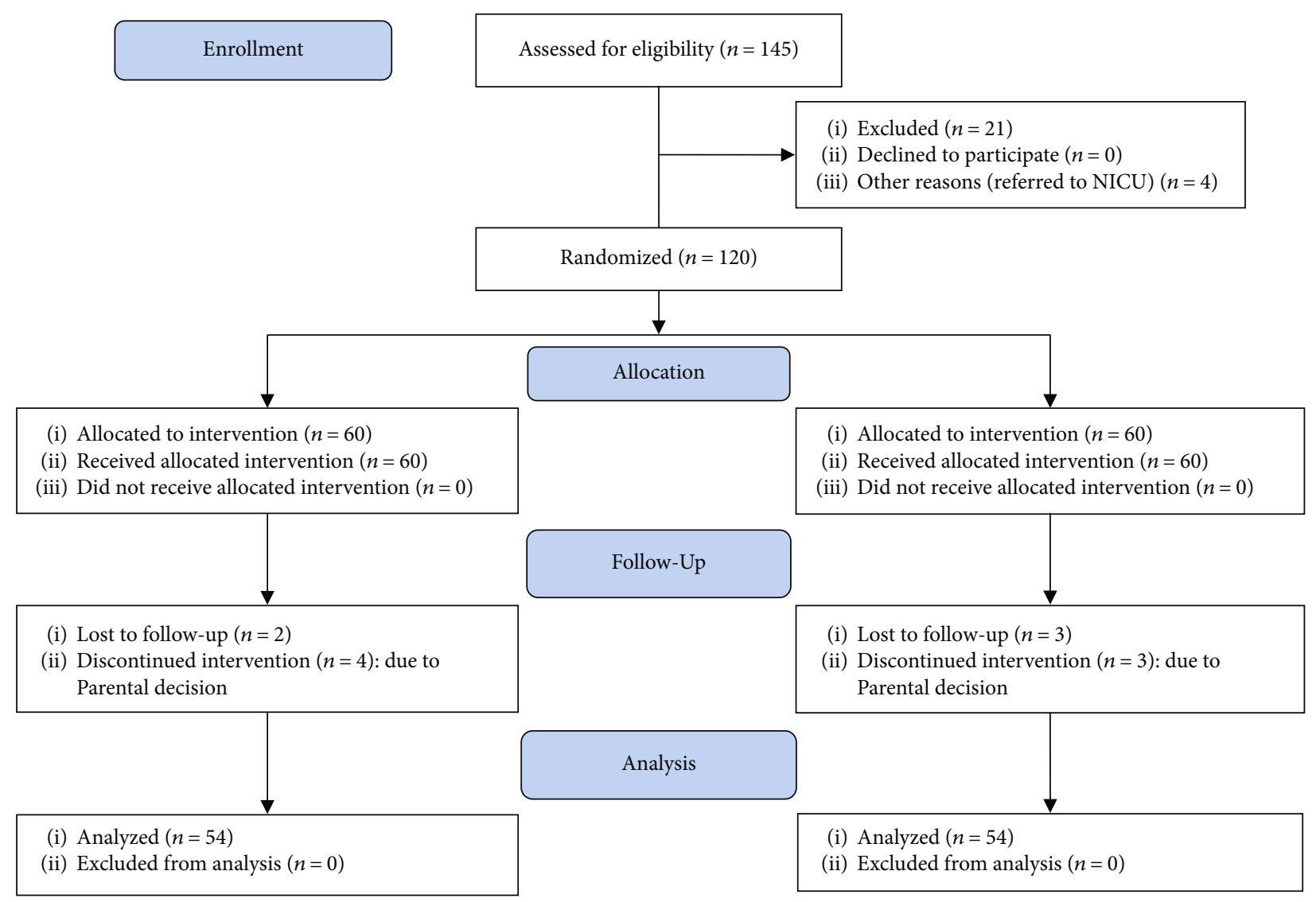

FIgURE 1: CONSORT flow diagram.

TABLE 2: Demographic characteristics in two intervention groups.

\begin{tabular}{|c|c|c|c|}
\hline Demographic characteristics & $\begin{array}{l}\text { Ranitidine plus metoclopramide } \\
\text { (group A) } n=54\end{array}$ & $\begin{array}{l}\text { Lansoprazole plus metoclopramide } \\
\text { (group B) } n=54\end{array}$ & $p$ value \\
\hline \multicolumn{4}{|l|}{ Gender } \\
\hline Girls, $n(\%)$ & $31(57.4 \%)$ & $28(51.9 \%)$ & 0.564 \\
\hline Boys, $n(\%)$ & $23(42.6 \%)$ & $26(48.1 \%)$ & \\
\hline Age at intervention, mean $\pm \mathrm{SD}$, days & $11.6 \pm 7.48$ & $10.22 \pm 6.861$ & 0.321 \\
\hline Birth weight, mean $\pm S D, g$ & $3189.5 \pm 428.1$ & $3219.5 \pm 371.1$ & 0.474 \\
\hline Weight at presentation, mean $\pm \mathrm{SD}, \mathrm{g}$ & $3193.6 \pm 516.4$ & $3205.8 \pm 532.4$ & 0.835 \\
\hline Gestational age at birth, mean $\pm \mathrm{SD}$, weeks \pm days & $38 \mathrm{w} \pm 3 \mathrm{~d}$ & $38 \mathrm{w} \pm 5 \mathrm{~d}$ & 0.216 \\
\hline Total scoring at presentation, mean \pm SD & $19.48 \pm 5.35$ & $20.35 \pm 4.88$ & 0.263 \\
\hline
\end{tabular}

irritability and lethargy, extraordinary crying, apnea or respiratory problem, and redness or cyanosis during or after feeding after one month. The response rate of the above clinical manifestations was similar in both groups.

The mean \pm SD score of preintervention clinical manifestations in group A was 19.52 \pm 5.18 that decreased to $9.31 \pm 4.57$ after one week of intervention $(p \leq 0.001)$ and $4.5 \pm 4.12$ after one month of intervention $(p \leq 0.001)$. The mean \pm SD score of preintervention clinical manifestations in group B was $20.5 \pm 4.92$ that decreased to 7.44 \pm 3.86 after one week of intervention $(p \leq 0.001)$ and $2.41 \pm 3.06$ after one month of intervention $(p \leq 0.001)$ (Table 5).

\section{Discussion}

The present randomized clinical trial study was conducted to compare the efficacy and safety of oral ranitidine plus metoclopramide with oral lansoprazole plus metoclopramide in the treatment of neonatal GERD resistant to conservative therapy and monotherapy.

Oral PPIs have been increasingly used in children and infants under one year of age for treatment of GERD despite lack of published evidence for improved outcomes and increasing concerns over adverse effects [21, 22].

PPIs have earned a global approval leading to less therapy disruption and less therapy changes in the first month of 


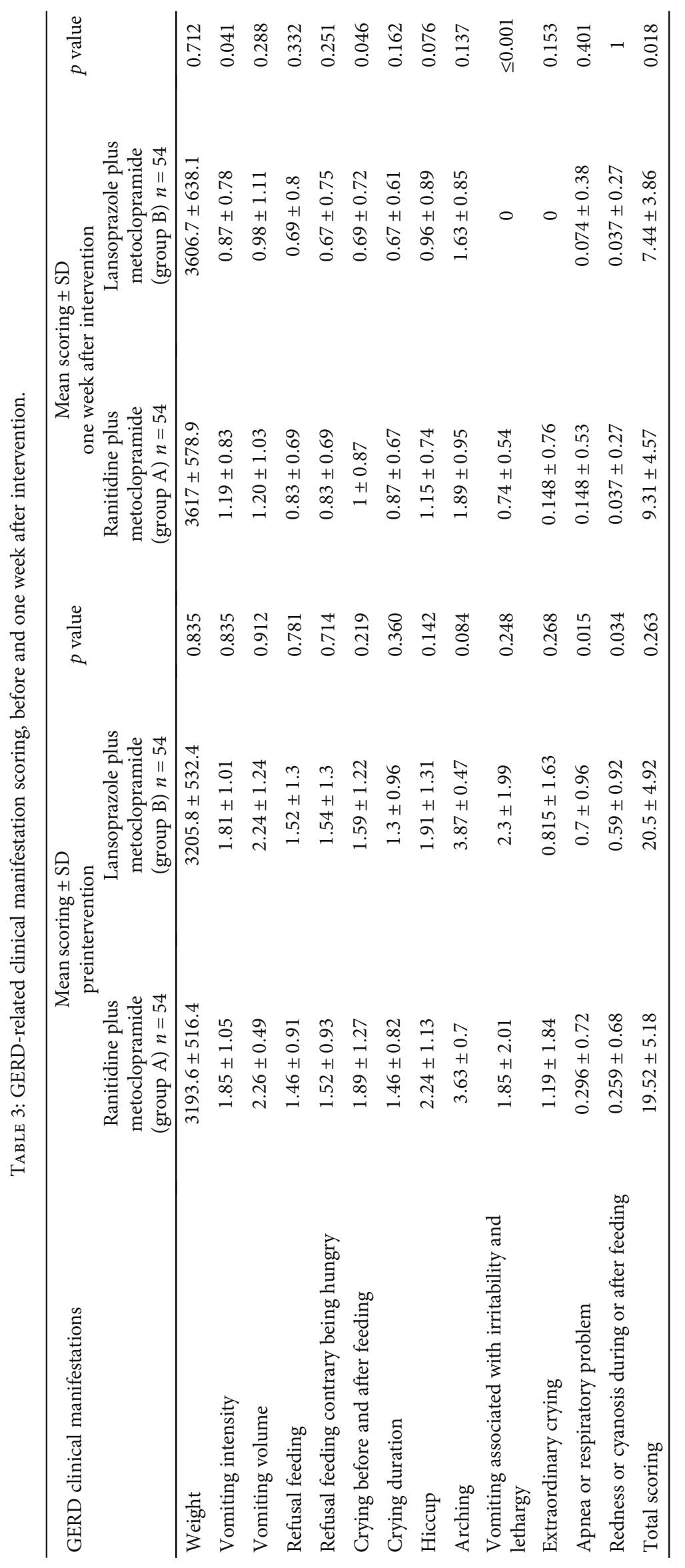




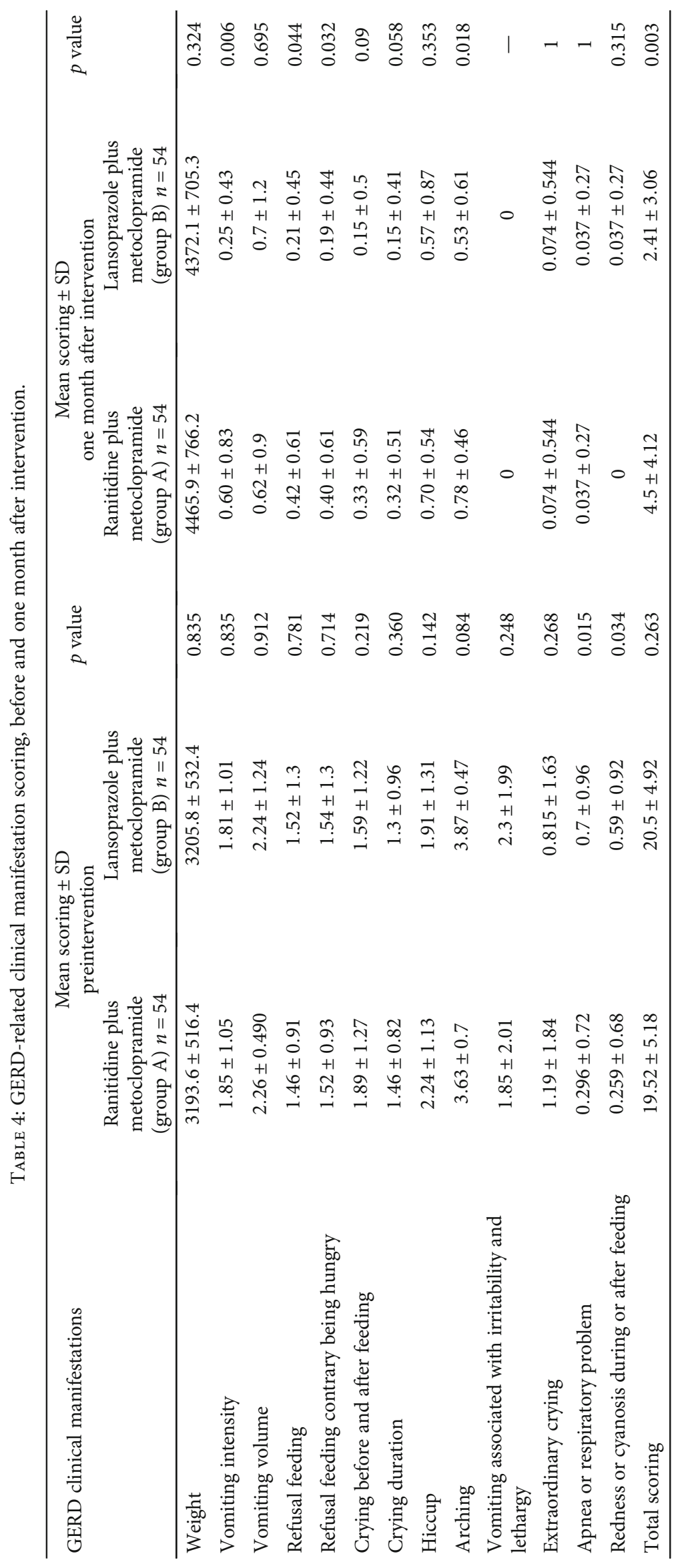


TABLE 5: The changes of GERD-related scoring of clinical manifestations and percentage of response rate one week and one month after intervention.

\begin{tabular}{|c|c|c|c|}
\hline The mean response rate & $\begin{array}{l}\text { Ranitidine plus metoclopramide } \\
\qquad \text { (group A) } n=54\end{array}$ & $\begin{array}{l}\text { Lansoprazole plus metoclopramide } \\
\qquad \text { (group B) } n=54\end{array}$ & $\begin{array}{l}\text { Intergroup } \\
{ }^{* *} p \text { value }\end{array}$ \\
\hline $\begin{array}{l}\text { Preintervention clinical manifestation scoring, } \\
\text { mean } \pm \text { SD }\end{array}$ & $19.52 \pm 5.18$ & $20.5 \pm 4.92$ & 0.263 \\
\hline $\begin{array}{l}\text { Overall clinical manifestation scoring, } \\
\text { one week after intervention, mean } \pm \text { SD }\end{array}$ & $9.31 \pm 4.57$ & $7.44 \pm 3.86$ & 0.018 \\
\hline $\begin{array}{l}\text { Percentage of response rate one week } \\
\text { after intervention, mean } \pm \mathrm{SD}\end{array}$ & $52.14 \pm 21.24$ & $64.38 \pm 15.07$ & \\
\hline $\begin{array}{l}\text { Overall clinical manifestation scoring, } \\
\text { one month after intervention, mean } \pm S D\end{array}$ & $4.5 \pm 4.12$ & $2.41 \pm 3.06$ & 0.003 \\
\hline $\begin{array}{l}\text { Percentage of response rate, one month } \\
\text { after intervention, mean } \pm S D\end{array}$ & $74.3 \pm 23.3$ & $88.47 \pm 13.18$ & \\
\hline Intragroup ${ }^{*} p$ value & $\leq 0.001$ & $\leq 0.001$ & $\leq 0.001$ \\
\hline
\end{tabular}

treatment $[8,22]$. The previous approach to the management of infantile GERD requiring acid suppression treatment was a "step-up" regimen in which ranitidine was administered as the first line of treatment and replaced with PPIs if the symptoms persisted despite using high-dose ranitidine [23]. According to an updated review on GERD in children, pharmacotherapy should be considered in the treatment of severe gastroesophageal reflux disease for patients who do not respond to conservative therapies. On the other hand, PPIs are favored over H2-receptor antagonists because of their superior efficacy [24]. Recent studies have demonstrated that the majority of symptoms in neonatal GERD are associated either with nonacid reflux or with acid reflux [25]. Despite the information presented above, PPIs have been rarely used as the first-line therapy for GERD treatment in infants and neonates due to few comparative studies versus H2RA.

To the best of our knowledge, very few clinical trials have compared the efficacy of H2RAs with PPIs and different PPIs with each other in pediatric GERD, especially in neonates and infants $[16,17]$. There are also few studies that have surveyed the safety of lansoprazole in the treatment of GERD in pediatrics and infants $[18,26,27]$.

Tolia et al. evaluated the safety of lansoprazole in the treatment of GERD in patients 1-12 years of age during 812 weeks. They administered two doses of lansoprazole including $15 \mathrm{mg}$ once daily in patients $\leq 30 \mathrm{~kg}$ and $30 \mathrm{mg}$ once daily in patients $>30 \mathrm{~kg}$ (mean dose $0.9 \mathrm{mg} / \mathrm{kg}$ ). No serious adverse effects were found related to lansoprazole. There were only few drug-related adverse effects after dose increment. Overall, their study showed that administration of lansoprazole was safe in children 1-12 years of age and well tolerated for 8-12 weeks [26].

Springer et al. found that lansoprazole was well tolerated after 5 days of administration and increased the intragastric $\mathrm{pH}$ in infants less than one year of age. A decrease in the frequency of GERD symptoms was also observed [18].

Khoshoo et al. studied the clinical efficacy of two dosing regimens of lansoprazole in infants of 3-7 months with
GERD diagnosed using I-GERQ-R scores of $\geq 16$. The patients were randomly assigned to receive lansoprazole either $15 \mathrm{mg}$ QD (group A) or $7.5 \mathrm{mg}$ BD (group B). The control group received an extensively hydrolyzed formula (group C). The I-GERQ-R score decreased by $33 \%$ in group A versus $67 \%$ in group B $(p<0.05)$. After two weeks of treatment, both groups showed a similar significant response rate (60\% versus 67\%) that was higher than group C (20\%). Although there was no difference in the clinical response rate of administering two dosing regimens of lansoprazole in infants with GERD, the twice-daily regimen showed a faster clinical response [27].

Among prokinetics, metoclopramide is a safe prokinetic if it is administered in a low-dose amount and a shortduration course [12]. As other prokinetics, metoclopramide increases the LES tone and gastric emptying [11].

Since no study has compared the efficacy and safety of metoclopramide plus ranitidine with metoclopramide plus lansoprazole in the management of neonatal GERD resistant to conservative therapy and monotherapy, this study was carried out.

In the present study, the total clinical improvement was $>50 \%$ after one week and $>70 \%$ after one month of intervention as defined as "a reduction in the I-GERQ-R score." The findings showed that the response rate was significantly higher in the lansoprazole plus metoclopramide group compared to the ranitidine plus metoclopramide group after one week $(64.38 \% \pm 15.07 \%$ vs. $52.14 \% \pm 21.24 \%, p \leq 0.001)$ and after one month of intervention $(74.3 \% \pm 23.3 \%$ vs. $88.47 \%$ $\pm 13.18 \%, p \leq 0.001)$. Treatment with lansoprazole plus metoclopramide improved all clinical manifestations better than ranitidine plus metoclopramide after one week while treatment with lansoprazole plus metoclopramide improved all clinical manifestations better than ranitidine plus metoclopramide except for feeding refusal, vomiting associated with irritability and lethargy, extraordinary crying, apnea or respiratory problems, and redness or cyanosis during or after feeding after one month. The response rate of the above clinical manifestations was similar in both groups. 
In the present study, the neonates with GERD showed a higher response rate to the combination of an acid suppressant and metoclopramide in comparison with monotherapy alone. It seems that the combination of an acid suppressant with metoclopramide had a cumulative hypertonic effect on the lower esophageal sphincter and a more rapid gastric emptying effect that led to a higher response rate in these patients.

There are some reports that acid suppressants may induce higher infection rates, necrotizing enterocolitis and mortality in premature infants [28-30]. According to a study of Kierkus et al. [31], PPIs are well tolerated in short-term use and are associated with mild to moderate side effects. However, more studies should be done to determine the efficacy and safety of acid suppressants in infants [22]. Metoclopramide may induce irritability, drowsiness, dystonic reaction, apnea, and emesis in infants [32]. In the present study, no adverse effects were observed for drugs used in each group.

This study had some limitations. It was limited to a healthy term population, so we suggest similar studies on term infants with more participants and premature infants too. The study was limited to 30 days and no long-term follow-up of the infants was reported. More researches on longer duration of intervention and longer-term outcomes are needed before firm conclusions can be reached. Future studies with a control group are also recommended.

\section{Conclusions}

The response rate was significant in each group after one week and one month of treatment, but it was significantly higher in the "lansoprazole plus metoclopramide" group compared with the "ranitidine plus metoclopramide" group. The combination of each acid suppressant with metoclopramide led to a higher response rate in comparison with monotherapy used before intervention.

\section{Data Availability}

The data used to support the findings of this study are available from the corresponding author upon request.

\section{Conflicts of Interest}

All authors declare that they have nothing to disclose, financially or otherwise. There is no conflict of interest.

\section{Acknowledgments}

The authors wish to thank the personnel of the Neonatal Clinic and Neonatal Ward of Bahrami Children Hospital. We also express our gratitude to the Research Development Center of Bahrami Children Hospital.

\section{References}

[1] R. Rosen, Y. Vandenplas, M. Singendonk et al., "Pediatric gastroesophageal reflux clinical practice Guidelines," Journal of Pediatric Gastroenterology and Nutrition, vol. 66, no. 3, pp. 516-554, 2018.
[2] B. Hegar, N. R. Dewanti, M. Kadim, S. Alatas, A. Firmansyah, and Y. Vandenplas, "Natural evolution of regurgitation in healthy infants," Acta Paediatrica, vol. 98, no. 7, pp. 11891193, 2009.

[3] P. M. Sherman, E. Hassall, U. Fagundes-Neto et al., "A global, evidence-based consensus on the definition of gastroesophageal reflux disease in the pediatric population," The American Journal of Gastroenterology, vol. 104, no. 5, pp. 1278-1295, 2009.

[4] I. Davies, S. Burman-Roy, M. S. Murphy, and on behalf of the Guideline Development Group, "Gastro-oesophageal reflux disease in children: NICE guidance," BMJ, vol. 350, no. jan14 5, p. g7703, 2015.

[5] J. R. Lightdale, D. A. Gremse, and Section on Gastroenterology, Hepatology, and Nutrition, "Gastroesophageal reflux: management guidance for the pediatrician," The Journal of Pediatrics, vol. 131, no. 5, pp. e1684-e1695, 2013.

[6] A. Randel, "AAP releases guideline for the management of gastroesophageal reflux in children," American Family Physician, vol. 89, no. 5, pp. 395-397, 2014.

[7] C. T. Ferreira, E. d. Carvalho, V. L. Sdepanian, M. B. Morais, M. C. Vieira, and L. R. Silva, "Doença do refluxo gastroesofagico: exageros, evidencias e a pratica clinica," Jornal de Pediatria, vol. 90, no. 2, pp. 105-118, 2014.

[8] R. M. Ward and G. L. Kearns, "Proton pump inhibitors in pediatrics. Mechanism of action, pharmacokinetics, pharmacogenetics and pharmacodynamics," Pediatric Drugs, vol. 15, no. 2, pp. 119-131, 2013.

[9] M. Tighe, N. A. Afzal, A. Bevan, A. Hayen, A. Munro, and R. M. Beattie, "Pharmacological treatment of children with gastro-esophageal reflux," Cochrane Database of Systematic Reviews, vol. 11, article CD008550, 2014.

[10] S. Salvatore, B. Hauser, A. Salvatoni, and Y. Vandenplas, "Oral ranitidine and duration of gastric $\mathrm{pH}>4.0$ in infants with persisting reflux symptoms," Acta Paediatrica, vol. 95, no. 2, pp. 176-181, 2006.

[11] A. M. Hibbs, "Gastrointestinal reflux and motility in the neonate," in Fanaroff and Martin's Neonatal-Perinatal Medicine: Diseases of Fetus and Infant, R. J. Martin, A. A. Fanaroff, and M. C. Walsh, Eds., pp. 1513-1521, Elsevier Saunders, Philadelphia, 11th edition, 2019.

[12] U. S. Food and D. Administration, "Metoclopramide-containing drugs," November 2013, http://www.fda.gov/Safety/ MedWatch/SafetyInformation/, Safety Alerts for Human Medical Products/ucm106942.html.

[13] D. Djeddi, G. Kongolo, C. Lefaix, J. Mounard, and A. Léké, "Effect of domperidone on QT interval in neonates," The Journal of Pediatrics, vol. 153, no. 5, pp. 663-666, 2008.

[14] S. A. Zamora, D. C. Belli, G. Ferrazzini, and B. Friedli, "Effects of cisapride on ventricular depolarization-repolarization and arrhythmia markers in infants," Neonatology, vol. 80, no. 1, pp. 30-34, 2001.

[15] R. K. Albert, J. L. Schuller, and COPD Clinical Research Network, "Macrolide antibiotics and the risk of cardiac arrhythmias," American Journal of Respiratory and Critical Care Medicine, vol. 189, no. 10, pp. 1173-1180, 2014.

[16] A. Zeneca, "AstraZeneca's review of actual PPI use in the treatment of infants with GERD," Briefing document for the Gastrointestinal Drugs Advisory Committee Meeting November 5, 2010: clinical experience related to the eslansoprasole clinical studies in patients $<1$ year of age with gastroesophageal reflux 
diseaseJanuary 2018, https://wayback.archive-it.org/7993/ $20170404152526 /$ https://www.fda.gov/downloads/ AdvisoryCommittees/CommitteesMeetingMaterials/Drugs/ GastrointestinalDrugsAdvisoryCommittee/UCM232029.pdf.

[17] P. A. Taheri, F. Mahdianzadeh, M. Shariat, and M. Sadeghi, "Combined therapy in gastro-esophageal reflux disease of term neonate resistant to conservative therapy and monotherapy: a clinical trial," Journal of Pediatric and Neonatal Individualized Medicine (JPNIM), vol. 7, no. 2, article e070201, 2018.

[18] M. Springer, S. Atkinson, J. North, and M. Raanan, "Safety and pharmacodynamics of lansoprazole in patients with gastroesophageal reflux disease aged $<1$ year," Paediatric Drugs, vol. 10, no. 4, pp. 255-263, 2008.

[19] F. Famouri, N. Zibanejad, P. Kabiri, and R. Kelishadi, "Comparison of hypoallergenic diets. Ranitidine in treatment of gastroesophageal reflux disease of infants: a randomized clinical trial," Iranian Journal of Pediatrics, vol. 27, no. 4, article e5343, 2017.

[20] L. Kleinman, M. Rothman, R. Strauss et al., “The infant gastroesophageal reflux questionnaire revised: development and validation as an evaluative instrument," Clinical Gastroenterology and Hepatology, vol. 4, no. 5, pp. 588-596, 2006.

[21] S. P. Nelson, S. Kothari, E. Q. Wu, N. Beaulieu, J. M. McHale, and O. H. Dabbous, "Pediatric gastroesophageal reflux disease and acid-related conditions: trends in incidence of diagnosis and acid suppression therapy," Journal of Medical Economics, vol. 12, no. 4, pp. 348-355, 2009.

[22] J. J. Barron, H. Tan, J. Spalding, A. W. Bakst, and J. Singer, "Proton pump inhibitor utilization patterns in infants," Journal of Pediatric Gastroenterology and Nutrition, vol. 4, pp. 421-427, 2007.

[23] E. Hassall, "Step-up and step-down approaches to treatment of gastroesophageal reflux disease in children," Current Gastroenterology Reports, vol. 10, no. 3, pp. 324-331, 2008.

[24] A. K. C. Leung and K. L. Hon, "Gastroesophageal reflux in children: an updated review," Drugs in Context, vol. 8, pp. 112, 2019.

[25] S. R. Orenstein, "Infant GERD: symptoms, reflux episodes \& reflux disease, acid \& non-acid reflux-implications for treatment with PPIs," Current Gastroenterology Reports, vol. 15, no. 11, p. 353, 2013.

[26] V. Tolia, G. Ferry, T. Gunasekaran, B. Huang, R. Keith, and L. Book, "Efficacy of lansoprazole in the treatment of gastroesophageal reflux disease in children," Journal of Pediatric Gastroenterology and Nutrition, vol. 35, Suppl 4, pp. S308S318, 2002.

[27] V. Koshoo and P. Dhume, "Clinical response to 2 dosing regimens of lansoprazole in infants with gastroesophageal reflux," Journal of Pediatric Gastroenterology and Nutrition, vol. 46, no. 3, pp. 352-354, 2008.

[28] G. Terrin, A. Passariello, M. De Curtis et al., "Ranitidine is associated with infections, necrotizing enterocolitis, and fatal outcome in newborns," Pediatrics, vol. 129, no. 1, pp. e40e45, 2011.

[29] V. S. Santos, M. S. Freire, R. N. S. Santana et al., "Association between histamine-2 receptor antagonists and adverse outcomes in neonates: a systematic review and meta-analysis," PLoS One, vol. 14, no. 4, article e0214135, 2019.

[30] R. N. S. Santana, V. S. Santos, R. F. Ribeiro-Júnior et al., "Use of ranitidine is associated with infections in newborns hospi- talized in a neonatal intensive care unit: a cohort study," BMC Infectious Diseases, vol. 17, no. 1, p. 375, 2017.

[31] J. Kierkus, G. Oracz, B. Korczowski, E. Szymanska, A. Wiernicka, and M. Woynarowski, "Comparative safety and efficacy of proton pump inhibitors in paediatric gastroesophageal reflux disease," Drug Safety, vol. 37, no. 5, pp. 309-316, 2014.

[32] A. M. Hibbs and S. A. Lorch, "Metoclopramide for the treatment of gastroesophageal reflux disease in infants: a systematic review," Pediatrics, vol. 2, pp. 746-752, 2006. 